\title{
ON THE PERSISTENCE OF LEADERSHIP OR LEAPFROGGING IN INTERNATIONAL TRADE*
}

\author{
BY \\ Massimo Motta, Jacques-François Thisse, And Antonio Cabrales ${ }^{\dagger 1}$ \\ Universitat Pompeu Fabra, Spain \\ Université Catholique de Louvain, Belgium, Ecole Nationale des Ponts et \\ Chaussées, France \\ Universitat Pompeu Fabra, Spain
}

\begin{abstract}
When two countries starting from different quality levels (reflecting different conditions on domestic market demands) open to trade, two possible equilibria arise. In the first, the quality leader maintains its position. In the second, leapfrogging occurs. However, the latter is possible only if the initial quality gap is not too wide. Further, when the risk dominance criterion is used, only the former equilibrium is selected. These results suggest that initial conditions (such as domestic market size or home demand preferences) are important factors in determining relative competitiveness of firms in international markets.
\end{abstract}

\section{INTRODUCTION}

In recent years, the study of imperfect competition models has allowed an impressive advance in the theory of international trade. However, the analysis of trade between countries showing asymmetric conditions has not caught much attention in the profession. Few exceptions can be recalled. Krugman (1980) shows that, in his now standard monopolistic competition model of trade, a country with large domestic demand ends up with higher wages at the equilibrium because of scale economies. Devereux and Lapham (1994) and Rivera-Bátiz and Xie (1993) analyze models with different endowments of knowledge and different sizes, and show that trade integration may have an adverse effect on specialization and growth of a country. Motta (1992) applies an oligopoly model of vertical differentiation to the analysis of trade between two countries that differ in size and finds conditions under which losses from trade may arise for a small country. Finally, Flam and Helpman (1987) consider a model with two countries endowed with an efficient and inefficient technology, respectively. They show that the advanced country supplies

* Manuscript received January 1995; revised March 1996.

†'E-mail: thisse@core.ucl.ac.be

${ }^{1}$ The authors acknowledge partial financial support from the European Union Human Capital and Mobility Project ERB4050PL930320 (Motta), the Center for Economic Policy Research's MIRAGE programme (Motta) and the Spanish Ministry of Education through DGICYT grants PB93-0398 (Cabrales) and PB92-1037 (Motta). We received help and comments from A. Bosch, T. Cordella, F. Delbono, V. Denicoló, D. Harhoff, S. Lutz, L. Rivera-Batiz, C. Scarpa, K. Stahl, and two anonymous referees. 
the top quality products while the backward country produces and exports the bottom quality ones. However, a switch in the pattern of production and trade may occur when technical progress is faster in the South than in the North.

Yet, such a small attention to trade between asymmetric countries is surprising. Trade liberalization processes between countries with very different characteristics are the rule rather than the exception and this raises questions about their effects. In particular, one may wonder whether trade integration will bring about more benefit to a country than to the other and to which extent historical advantages tend to persist after trade. A similar question has been recently addressed by Brezis et al. (1993). These authors question the idea supported by endogenous growth models that if a country acquires an advantage in technologically progressive sectors then this advantage will tend to grow over time. They show that a lagging nation may be able to 'leapfrog' a rival country as a reaction to a major exogenous change in technology. The intuition is that a country experienced with an old and successful technology will be less ready to adopt the new one than a backward country. A similar argument has been proposed in a different context by Nelson and Winter (1985), who underline that successful firms may be less eager to change, facilitating the task of the followers in the presence of exogenous changes in the economic environment. Ohyama and Jones (1994) offer a similar explanation for leapfrogging, by putting it in terms of comparative advantages. In their paper a leading firm is overtaken by a laggard firm because the former's absolute superiority in an existing technology gives the latter a comparative advantage in the new technology.

The same type of issue, but in a different perspective, can be found in the industrial organization literature, which aims at understanding whether the leadership of a firm in a given sector tend to persist or to shrink over time (see, e.g., Reinganum 1985, Dasgupta and Stiglitz 1988, Gruber 1992, Budd et al. 1993).

In this paper we want to investigate whether a country supplying low-quality products can catch up with a rival country supplying high-quality products when both have access to the same technology. To this end, we consider an oligopolistic model with vertical product differentiation in a two-country setting. Our main concern is to understand the role of domestic conditions in determining the international success of a firm. When countries open to trade, firms start from an initial level of quality of their product which depends on local characteristics of demand. The larger and/or more sophisticated the home demand, the higher the quality supplied to the domestic customers. In other words, the autarky equilibrium determines the initial conditions of the trade game. Since firms face a larger (international) market and more competition, the autarky choices of quality and price are generally not the optimal ones under trade. Firms are then given the possibility to update their quality-price decisions by paying adjustment costs, which are given by an increasing function of the difference between the desired quality and the initial one (prices can be adjusted costlessly). In general, firms would like to be the quality leader at the equilibrium since this would yield higher profits.

It turns out there exist multiple strict Nash equilibria. In the first Nash equilibrium, the leader of the industry in the trade situation is the firm that provided the higher quality at autarky: ${ }^{2}$ it belongs to the larger (or richer) country. We call it 
'persistence of dominance' equilibrium. In the other Nash equilibrium (we call it 'change of leadership' equilibrium or 'leapfrogging' equilibrium), the new leader comes from the smaller (or poorer) country. It starts with a lower-quality product than its rival when trade opens, but then manages to catch up and get the lead through an additional investment in quality. In other words, we identify the possibility that 'leapfrogging' arises despite the fact that no exogenous change in the available technology occurs.

The existence of multiple equilibria is subject to two main qualifications, however, Firstly, when the countries are very different the only possible equilibrium arising is the one where there is persistence of leadership. Intuitively, the additional effort that the laggard should make to take the lead is so large, given the initial disadvantage, that the quality it would select would be easily overtaken by the leader.

Secondly, if the risk dominance criterion of equilibrium selection (Harsanyi and Selten 1988) is used, the only remaining Nash equilibrium will be the persistence of dominance equilibrium. Very loosely speaking, risk can then explain why the leapfrogging equilibrium may not be actually selected. To catch up with the initial gap, a higher investment should be made by the laggard than by the current leader. The higher the investment required by such a leapfrogging strategy by the laggard, the higher the risk it would involve (and the more likely that the firm has to rely on outside funds to finance the operation, thus increasing its cost). This may give some intuition about the selection of the persistence of leadership equilibrium.

These two results put together suggest that historical (or domestic) conditions matter a lot on the international marketplace. Firms that come from countries with a larger market, or where potential consumers are more eager to get better products, tend to develop higher quality products, which puts them at an advantage in international competition. Note that the role played by the national market to determine firms' success has been already suggested by Linder (1961), and formalized successively by Krugman (1980), and Dinopoulos (1988) in the context of monopolistic competition and (spatial) horizontal product differentiation, respectively. In these models, however, the issue of persistence or change of leadership has not been addressed.

Our results also seem to fit quite closely the evidence reported in the business literature. For example, Porter (1990) underlines the importance of home demand conditions as a determinant of a national competitive advantage in an industry. In particular, demand conditions should be understood not only in terms of quantity but also of quality (Porter says the latter is even more important, 1990 p. 86). The presence of sophisticated consumers putting pressure on national firms to raise the

\footnotetext{
${ }^{2}$ An alternative way to express this result is to say that the leader when firms update their qualities is the same as the leader at the short-run trade equilibrium. Indeed, if firms were allowed to change their prices but not their qualities at the very moment trade is allowed (or if adjustment costs of quality are prohibitive) then the leader in the international market is the firm that supplies the higher quality at autarky. See Shaked and Sutton (1984) and Motta (1992) for an analysis of short-run trade effects in vertical differentiation models.
} 
quality of their products and services turns out to be a crucial element in the international success of a firm. Unusually stringent local needs and demand sophistication explain many stories of competitive advantage:

Scandinavian firms, for example, did well in paper plants, dams, bridges, ports, and hydroelectric power generation facilities. Italian firms did well in road and infrastructure projects, drawing on experience in coping with difficult and varied Italian terrain. German firms did well in constructing chemical and metallurgically based process plants. Japanese firms were successful in the construction of steel plants, shipyards, earthquake-proof buildings, railways, subways and other mass transit systems, dams (Japan generates a significant amount of electricity from hydropower), and aquaculture facilities (Porter 1990, p. 269).

This is an outcome that our model fully captures.

The asymmetries that we have emphasized so far are generated by the interaction of different demands in the different countries with an initial phase of autarky. There is, however, an alternative interpretation that would produce substantially similar results without using a dynamic model. Imagine that the products to be sold have an intrinsic exogenous level of quality that is country-specific, and that industrial processes may enhance that level (or the perception thereof) at a (quadratic) cost of the difference between the desired level and the exogenous level. In that case, two firms established in different countries producing in an international market would face an asymmetry derived from different initial endowments of quality. The changes in the model that would follow from this interpretation would be minor and the results would be essentially unaltered.

The remainder of the paper is organized as follows. Section 2 introduces the model to the reader and finds the autarky equilibrium. Section 3 analyzes the impact of international trade. Section 4 uses the risk dominance criterion to select between the equilibria of the trade game. Section 5 concludes the paper.

\section{THE MODEL AND THE AUTARKY CASE}

Consider two countries $A$ and $B$ with a single firm each. ${ }^{3}$ There are two goods, a differentiated product whose characteristics are to be chosen by the firms, and a numéraire that can be consumed or used to carry out activities that determine the quality of the differentiated product (such activities can be thought of as research and development investments, or advertising outlays). Each country has an initial endowment of the numéraire. In country $j(j=A, B)$, there is a population uniformly distributed over the interval $\left[0, \bar{\theta}^{j}\right]$ with density $S^{j}$. If a product of quality $q$ is available in country $j$, the utility of a consumer of type $\theta=\left[0, \bar{\theta}^{j}\right]$ is given by

$$
U_{\theta}(q, m)=\theta q+m
$$

where $m$ denotes the amount of the numéraire bought by this consumer, whose income is given, and large enough for the consumer to be able to buy if she wants to. When the price of the differentiated product is $p$ and its quality $q$, a consumer buys

\footnotetext{
${ }^{3}$ For simplicity, we have chosen to develop our analysis in the context of a partial equilibrium model. However, it could be recast as a general equilibrium model.
} 
if and only if his net surplus

$$
C S_{\theta}=\theta q-p
$$

is positive, so that the marginal consumer is at

$$
\hat{\theta}^{j}=\frac{p}{q} .
$$

Producing a good of quality $q$ involves constant marginal cost of producing the output (that we normalize to zero) and research and development (or advertising) expenditures given by $q^{2} / 2$ units of the numéraire. ${ }^{4}$ Accordingly, the national surplus generated by a product of quality $q$ in country $j$ is given by

$$
W^{j}=\frac{S^{j}}{2}\left[\left(\bar{\theta}^{j}\right)^{2}-\left(\hat{\theta}^{j}\right)^{2}\right] q-\frac{q^{2}}{2} .
$$

The firm located in country $j$ chooses its quality and price in order to maximize its profit given by

$$
\pi=S^{j}\left(\bar{\theta}^{j}-\hat{\theta}^{j}\right) p-\frac{q^{2}}{2}
$$

It is readily verified that the profit-maximizing choices in country $j$ are such that

$$
\begin{aligned}
& \bar{q}^{j}=\frac{S^{j}\left(\bar{\theta}^{j}\right)^{2}}{4} \\
& \bar{p}^{j}=\frac{\bar{\theta}^{j}}{2} \bar{q}^{j}=\frac{1}{8} S^{j}\left(\bar{\theta}^{j}\right)^{3} .
\end{aligned}
$$

Introducing (6) and (7) into (3) shows that the firm always supplies half of the market. Since $\bar{\theta}^{j} / 2$ is also the mean of the distribution, we see that both quality and price increase with the mean when the mass of consumers is constant. Intuitively, when the marginal willingness-to-pay of the average consumer is larger, the firm finds it optimal to improve its quality and to charge a higher price. Similarly, ceteris paribus, an increase in the consumer density leads the firm to raise both its quality and price because the burden of quality improvement falls on fixed costs. Evaluating the national surplus (4) at (6) and (7) yields

$$
\bar{W}^{j}=\frac{1}{16}\left(S^{j}\right)^{2}\left(\bar{\theta}^{j}\right)^{4}
$$

\footnotetext{
${ }^{4}$ Note that these are fixed costs of quality, which are sunk at the market competition stage of the game.
} 


\section{THE IMPACT OF INTERNATIONAL TRADE}

Assume now that the two countries have the same population $\left(S^{j} \bar{\theta}^{j}\right)$. This assumption allows us to neutralize our analysis from market size effects. Without loss of generality, let $S^{A}=1$ and $\bar{\theta}^{A} \geq \bar{\theta}^{B}$. Hence, it must be that $S^{B}=\bar{\theta}^{A} / \bar{\theta}^{B}$ and that $\bar{q}_{A} \geq \bar{q}_{B}$. Furthermore, we suppose that the two countries have access to the same technology in producing the differentiated product. In other words, countries are identical except for the average marginal willingness-to-pay (or, in more business-like terms, except for the sophistication of demand). Under these assumptions, it is readily verified that in autarky the quality produced by the firm located in country $A$ is higher than the quality produced in country $B$. The former firm can then be seen as the 'quality leader' when the economies are open to international trade.

We are fully aware that our formulation obviously implies lack of perfect foresight by the agents. When they decide on their autarky choice of quality, firms do not anticipate that trade will open at a later stage. In other words, firms attach a zero probability to the event that trade opens and when it does, they are taken completely by surprise. Although not always unrealistic (firms certainly did not expect that Germany would be reunified before the Berlin Wall fell) our assumption may be thought as not completely satisfactory. However, the reader should consider that our purpose is to analyze the role historical conditions play when trade liberalization occurs. Among the many possible assumptions that we may have used to describe the initial condition of the trade game, we think that the autarky equilibrium gives a reasonably acceptable one. ${ }^{5}$

In our formalization, the only difference between the two countries is that the average propensity to pay for quality is higher in country $A$. However, interpreting country $A$ as being the richer or the larger country is equally possible within this model. As for the interpretation in terms of citizens' wealth, we should: (i) notice that one would expect preference for quality-expressed here by the parameter $\theta$-to be positively correlated with incomes; (ii) observe that in the type of models studied here higher taste for quality can be associated to lower marginal utility of income and therefore higher income (Tirole 1988, p. 86). As for the interpretation in terms of size differences, one can observe that if the density of consumers in country $A$ were equal to the density of consumers in country $B\left(S^{A}=S^{B}\right)$ then the market size of $A$ would be bigger, and in turn the quality advantage enjoyed by country $A$ 's firm over its rival would be even higher. Hence, all the results obtained below would be strengthened, in the sense that the leapfrogging equilibrium would be even less likely to occur. The same is true for the case where $S^{A}>S^{B}$, with $\bar{\theta}^{A}$ equal or larger than $\bar{\theta}^{B}$. This means that we could interpret country $A$ as being the 'large' country and country $B$ as being the 'small' country.

We suppose that only one firm operates in each country. In the Appendix we show sufficient conditions under which a monopoly arises endogenously in each

\footnotetext{
${ }^{5}$ Another interpretation is to view the initial quality of each firm as the quality endowment resulting from natural conditions that prevail in each country. As we said in the Introduction, this alternative formalization would lead to similar results.
} 
market at the autarky equilibrium. In particular, it is shown there that if $\bar{\theta}_{B}>$ $.21926 \bar{\theta}_{A}$, then the assumption on market demand in the two countries is compatible with the assumption of monopoly in each country under autarky.

We assume that the numeraire is the same for both countries and that the differentiated product can be shipped from one country to the other at no cost. When trade is open, we also assume that firms perceive the two markets are segmented (for instance, institutional constraints prevent arbitrage between different countries). ${ }^{6}$ Because they now face an enlarged market, firms have an incentive to modify their quality choices before competing in prices. In so doing, firms incur adjustment costs that depend only upon the quality change and are given by $\left(q_{i}-\bar{q}_{j}\right)^{2} / 2$, where $q_{i}(i=1,2)$ is the desired level of quality under trade and $\bar{q}_{j}$ is the initial quality, as defined by expression (6) above. ${ }^{7}$ Consequently, the incremental cost increases with the quality change, but its variation is independent of the initial quality level. The latter assumption means that the technology involves no a priori bias in favor of the top or bottom quality firm.

Suppose without loss of generality that $q_{1}>q_{2}$. The consumer in country $j$ indifferent between buying from either firm is denoted $\hat{\theta}_{12}^{j}$, while the consumer indifferent between buying or not buying the differentiated product is $\hat{\theta}_{2}^{j}=p_{2}^{j} / q_{2}^{j}$. It is immediate that

$$
\hat{\theta}_{12}^{j}=\frac{p_{1}^{j}-p_{2}^{j}}{q_{1}-q_{2}}, \quad \text { for } j=A, B \text {. }
$$

The national surplus of country $j=A, B$, after the opening to international trade is given by:

$$
W^{j}=\frac{S^{j}}{2}\left[\left(\left(\bar{\theta}^{j}\right)^{2}-\left(\hat{\theta}_{12}^{j}\right)^{2}\right) q_{1}+\left(\left(\hat{\theta}_{12}^{j}\right)^{2}-\left(\hat{\theta}_{2}^{j}\right)^{2}\right) q_{2}\right]+p_{i}^{k} X_{i}^{k}-p_{h}^{j} X_{h}^{j}-\frac{\left(q_{i}-\bar{q}_{j}\right)^{2}}{2}
$$

when firm $i=1,2$ is located in country $j$, and firm $h \neq i$ is located in country $k \neq j$. In this expression, $X_{i}^{k}\left(X_{h}^{j}\right)$ denotes exports, that is, the quantity sold by firm $i(h)$ on the foreign market $k(j)$.

\footnotetext{
${ }^{6}$ We shall briefly deal with the case of integrated markets at the end of this section.

${ }^{7}$ More generally, the cost function could be written as $C\left(q_{i}, \bar{q}_{j}\right)=\alpha q_{i}^{2} / 2+\left(q_{i}-\bar{q}_{j}\right)^{2} / 2$, where the first term in the right-hand side stands for the fixed per-period cost of quality and the second term for the adjustment cost of quality. Here we choose to concentrate on the adjustment cost only and assume that $\alpha=0$. In so doing, we account for history and link the trade equilibrium to the initial conditions. Indeed, without the second term, the trade equilibrium would be completely independent of the domestic conditions. On the other hand, we can discard the first term because $\alpha>0$ would not affect the nature of our results. Indeed, if the laggard firm had to pay not only the adjustment cost but also the fixed cost of reaching a given quality, leapfrogging would be less likely to occur. By adopting such a formulation the reader might think that we would make it too difficult for leapfrogging to arise.
} 
The profits of a firm under international trade are defined as follows:

$$
\begin{aligned}
& \pi_{1}=\left(\bar{\theta}^{A}-\hat{\theta}_{12}^{A}\right) p_{1}^{A}+S^{B}\left(\bar{\theta}^{B}-\hat{\theta}_{12}^{B}\right) p_{1}^{B}-\frac{\left(q_{1}-\tilde{q}\right)^{2}}{2} \\
& \pi_{2}=\left(\hat{\theta}_{12}^{A}-\hat{\theta}_{2}^{A}\right) p_{2}^{A}+S^{B}\left(\hat{\theta}_{12}^{B}-\hat{\theta}_{2}^{B}\right) p_{2}^{B}-\frac{\left(q_{2}-\tilde{q}\right)^{2}}{2}
\end{aligned}
$$

where $\tilde{q}$ is $\bar{q}_{A}$ if the firm was the quality leader at autarky, and $\bar{q}_{B}$ otherwise. This corresponds to the two different scenarios discussed in the Introduction, that is, the one of persistent leadership and the case of leapfrogging.

Consider a pair of given qualities. The equilibrium prices of the corresponding subgame (which indirectly depend on $S^{j}$ through the choice of qualities) are:

$$
\begin{aligned}
& p_{1}^{j *}=\frac{2 \bar{\theta}^{j} q_{1}\left(q_{1}-q_{2}\right)}{4 q_{1}-q_{2}} \\
& p_{2}^{j *}=\frac{\bar{\theta}^{j} q_{2}\left(q_{1}-q_{2}\right)}{4 q_{1}-q_{2}} . \quad j=A, B
\end{aligned}
$$

We could also write expression (12a) as:

$$
p_{1}^{j *}=\frac{4\left(q_{1}-q_{2}\right)}{4 q_{1}-q_{2}} q_{1} \frac{\bar{\theta}^{j}}{2}
$$

By comparing this expression with (7), it appears that the autarky price in (7) can be seen as a special case of (12a).

Note also that although the national markets are segmented in prices, they are integrated in terms of qualities since each firm offers the same quality on each market. ${ }^{8}$ Put in another way, each firm chooses its quality in order to maximize the sum of its profits on each market net of the adjustment costs, given the prices (12a) and (12b):

$$
\begin{array}{r}
\pi_{1}\left(q_{1}, q_{2}\right)=\frac{4 \bar{\theta}_{A} q_{1}^{2}\left(q_{1}-q_{2}\right)\left(\bar{\theta}_{A}+\bar{\theta}_{B}\right)}{\left(4 q_{1}-q_{2}\right)^{2}}-\frac{\left(q_{1}-\bar{q}_{j}\right)^{2}}{2} \\
\pi_{2}\left(q_{1}, q_{2}\right)=\frac{\bar{\theta}_{A} q_{1} q_{2}\left(q_{1}-q_{2}\right)\left(\bar{\theta}_{A}+\bar{\theta}_{B}\right)}{\left(4 q_{1}-q_{2}\right)^{2}}-\frac{\left(q_{2}-\bar{q}_{k}\right)^{2}}{2} . \\
j, k=A, B \text { and } j \neq k .
\end{array}
$$

\footnotetext{
${ }^{8}$ A similar approach is adopted by Venables (1990), where firms choose a single capacity for the whole production but choose different prices in each market.
} 
Since the equilibrium qualities depend on the qualities produced under autarky as well as on the taste preferences of consumers in the two countries, the determination of the equilibrium is especially complex, though we use a simple model.

Because no analytical expression can be found for the equilibrium of the quality game, we have solved it for different values of $\bar{\theta}^{A}$, using the computer program Mathematica. All the results are qualitatively the same for different values of this parameter. Hence, we characterize here the equilibrium for $\bar{\theta}^{A}=10$, for the sake of simplicity. Thus $\bar{\theta}^{B}$ may vary between 0 and 10 . There are two candidate equilibria, which are given by the two quality pairs that satisfy the first-order conditions applied to (13a) and (13b). (For the full analysis of the equilibrium, the reader is referred to Motta et al., 1995.)

In one candidate equilibrium, the leader is the firm from country $A$, which had the higher quality under initial (autarky) conditions: $q_{1}=q_{A}$ and $q_{2}=q_{B}$. In the other, the leader is the firm from country $B: q_{1}=q_{B}^{\prime}$ and $q_{2}=q_{A}^{\prime}$. These candidate equilibria are obtained subject to the condition that firm $i$ provides the higher quality and firm $j$ the lower quality. However, for the candidate equilibria to be equilibria we must check that firm $i$ (respectively, firm $j$ ) does not find it profitable to deviate and produce a lower (respectively, higher) quality than its rival. In other words, the firm supposed to be the quality leader should not have an incentive to provide a quality lower than its competitor; and vice versa. We now show under which conditions these candidate equilibria are the Nash equilibria of the quality game as depicted in Figure 1.

Figure 2 shows that the persistence of leadership $\left(q_{1}=q_{A}, q_{2}=q_{B}\right)$ is always an equilibrium. Indeed, at this quality pair, the firms earn profits $\pi_{A}$ and $\pi_{B}$. If the firm

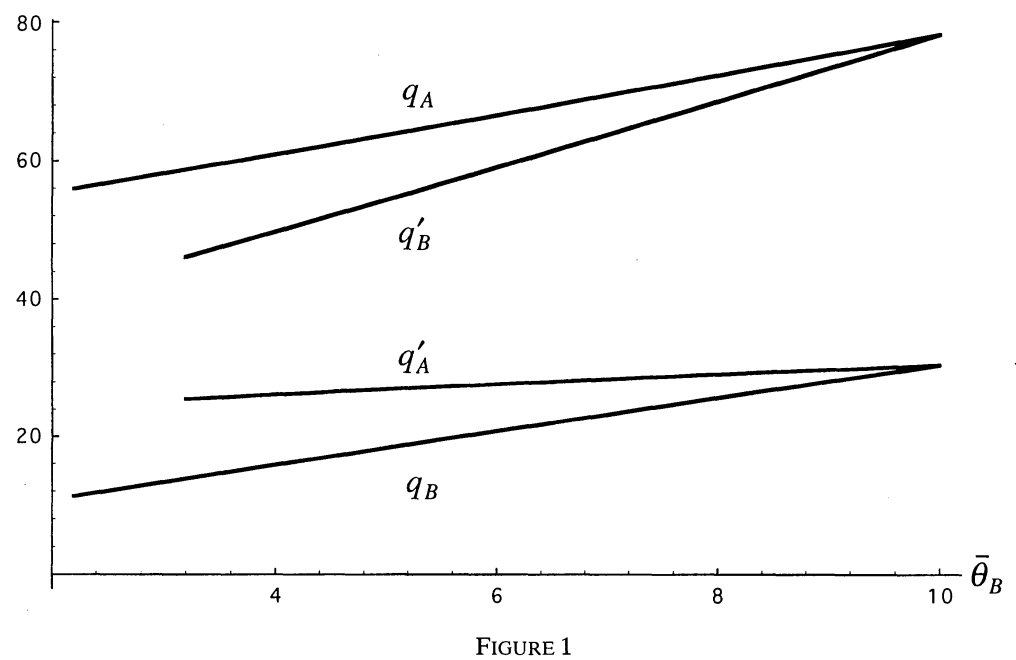

QUALITIES IN THE PERSISTENT LEADER EQUILIBRIUM $\left(q_{j}\right)$ AND IN THE CHANGE OF LEADERSHIP EQUILIBRIUM $\left(q_{j}^{\prime}\right)$, FOR COUNTRY $j=A, B$ 


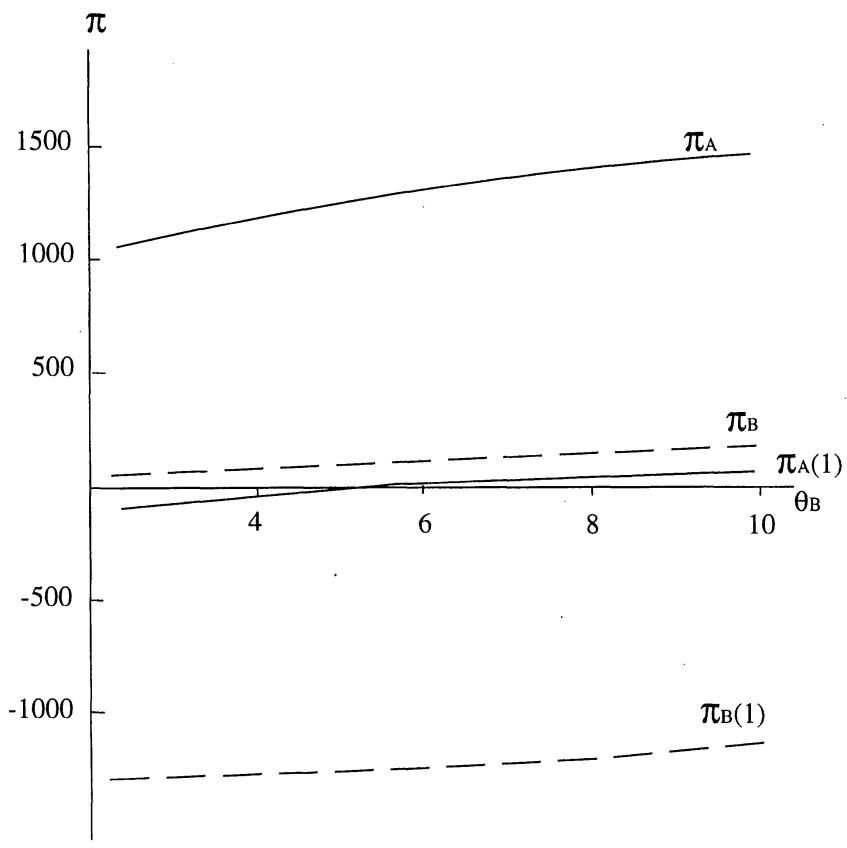

FIGURE 2

ANALYSIS OF THE EXISTENCE OF EQUILIBRIUM IN THE CASE OF PERSISTENCE OF LEADERSHIP: $\pi_{j}$ DENOTES PROFIT OF FIRM $j=A, B$ (SOLID AND DASHED LINES, RESPECTIVELY) AT THE CANDIDATE EQUILIBRIUM AND $\pi_{j}(l)$ THE PROFIT FROM THE OPTIMAL DEVIATION

from country $A$ decided to deviate and to produce the best possible quality subject to this quality being lower than $q_{B}$, it would obtain lower profits $\pi_{A}(l)$. Likewise, the firm from country $B$ does not find it profitable to deviate and to produce the higher quality. The leader produces a quality $q_{A}$ that is much higher than the initial quality produced by the firm from country $B$. If the latter tried to catch up with the rival firm's quality, it would have to incur a big adjustment cost. But to catch up would not be enough, since price competition would reduce to zero gross profits despite the major investment in quality. The firm from country $B$ should then significantly increase its quality beyond the candidate equilibrium quality $q_{A}$. However, this would increase so much its adjustment costs that the highest profits $\pi_{B}(l)$ it can obtain by deviating would be negative.

Figure 3 analyzes the case of 'change of leadership' along the same lines. In this case, though, the firm from country $A$ may have an incentive to deviate from the candidate equilibrium quality. Indeed, when country $B$ 's demand shows much less preference for quality than country $A$ 's, the firm located in country $B$ starts the international trade game with a quality disadvantage. Given the adjustment costs it has to incur to reach the desired quality level, the latter cannot be very large (notice 


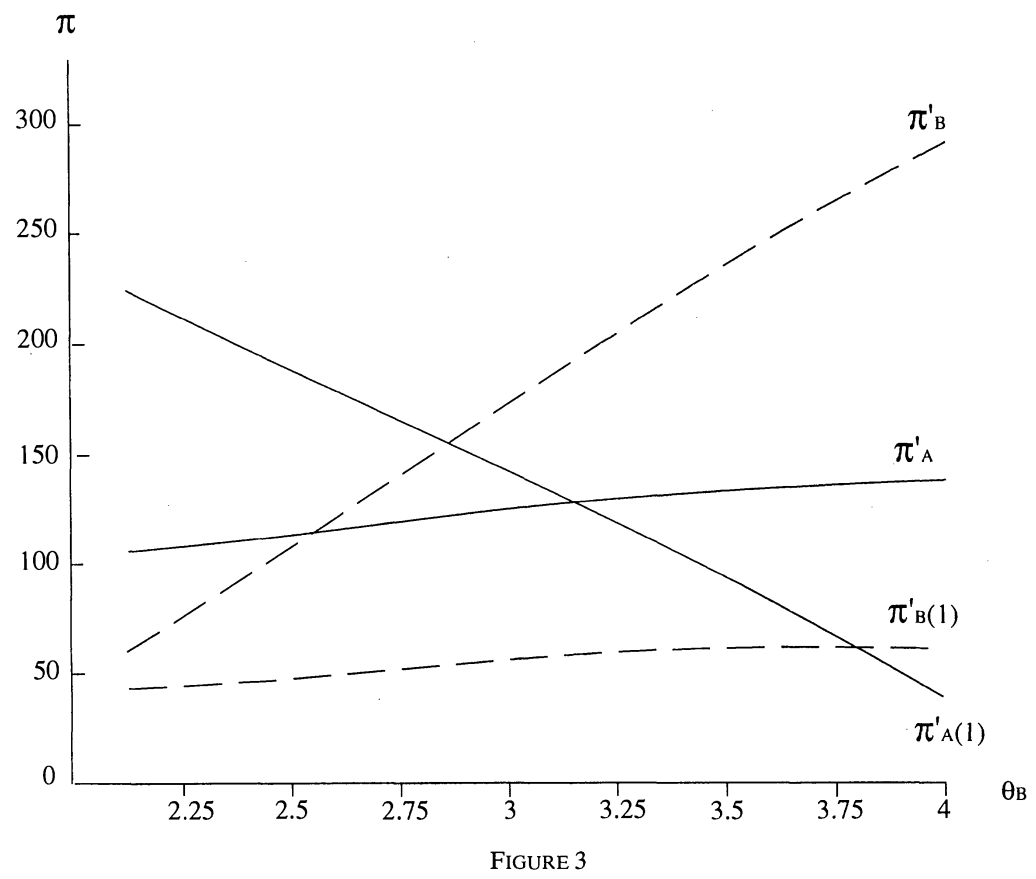

ANALYSIS OF THE EXISTENCE OF EQUILIBRIUM IN THE CASE OF CHANGE OF LEADERSHIP: $\pi_{j}^{\prime}$ DENOTES PROFIT OF FIRM $j=A, B$ (SOLID AND DASHED LINES, RESPECTIVELY) AT THE CANDIDATE EQUILIBRIUM AND $\pi_{j}^{\prime}(l)$ THE PROFIT FROM THE OPTIMAL DEVIATION

from Figure 1 that the lower $\bar{\theta}_{B}$ the lower $q_{B}^{\prime}$ ). Therefore, the additional investment cost made by the firm from country $A$ to select a quality sufficiently higher than $q_{B}^{\prime}$ is the more affordable the lower $\bar{\theta}_{B}$. Figure 1 also shows that the best quality choice that the firm from country $A$ can do conditional on its rival choosing the candidate equilibrium quality gives it a profit $\pi_{A}^{\prime}(l)>\pi_{A}^{\prime}$ for $\bar{\theta}_{B}<3.2$. The former has then an incentive to deviate by providing the higher quality. In other words, whereas the persistent leader equilibrium exists for the whole set of parameter values, the 'change of leadership' equilibrium exists only when $\bar{\theta}_{B}$ exceeds some critical value, that is, $\bar{\theta}_{B} \geq 3.2$. This explains why in Figure 1 the equilibrium qualities corresponding to the 'leapfrogging' equilibrium are drawn only for these values of the parameter.

Figure 4 shows welfare in each country under the two types of equilibria, where they exist. First of all, one notices that the welfare of a country is always higher when the domestic firm is the quality leader at the trade equilibrium: $W_{A}>W_{A}^{\prime}$ and $W_{B}^{\prime}>W_{B}$. This is mainly because the equilibrium profit earned by the top quality firm is always higher than the profit earned if it were the bottom quality firm. Secondly, welfare levels are increasing with $\bar{\theta}_{B}$. This is because the qualities also increase with $\bar{\theta}_{B}$, which has a positive effect on consumer surplus. The closer the market demands of 


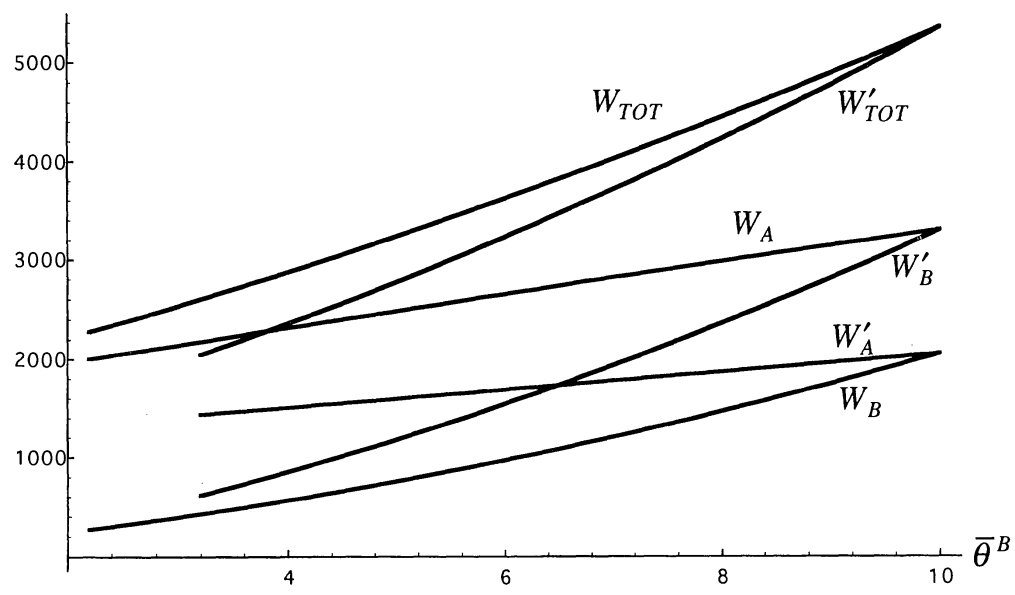

FIGURE 4

COUNTRY AND WORLD WELFARE IN THE PERSISTENT LEADER EQUILIBRIUM $\left(W_{j}, W_{T O T}\right)$ AND IN THE CHANGE OF LEADERSHIP EQUILIBRIUM $\left(W_{j}^{\prime}, W_{T O T}^{\prime}\right)$, FOR $j=A, B$

the two countries are, the higher the initial quality of country $B$ 's firm. In turn, this means that this firm can afford a higher level of quality (it has to pay lower adjustment costs for any given level of desired quality) and that the rival firm has to push upward its desired quality level. Thirdly, the comparison of world welfare levels shows that the more efficient equilibrium is the one where there is persistence of leadership. This market configuration allows to save on adjustment costs and to reach higher levels of quality than in the case of change of leadership.

We have so far analyzed international trade under the assumption that firms can charge different prices in the two markets they face. In some cases, firms cannot price discriminate because of legal constraints or because of arbitrage by consumers. It can be shown that the results obtained under segmented and integrated markets are very similar. As in the case analyzed here, under the assumption of integrated markets the persistent leader equilibrium always exists, whereas the leapfrogging equilibrium exists only when the two markets are not too different, that is, $\bar{\theta}^{B} \geq 3.95$ (Motta et al., 1995). By comparing the equilibrium values under the two alternative market pricing systems, it turns out that qualities and profits are lower under integrated markets than under segmented markets for either equilibrium and each firm, provided that the quality leader supplies both markets. Since higher profitability represents an incentive to invest in quality, the consumers enjoy higher qualities under segmented markets. This explains why world welfare is higher under segmented markets (Motta et al., 1995). ${ }^{9}$

\footnotetext{
${ }^{9}$ This result invites us to reconsider the claim made in the international trade literature that market integration is socially better than market segmentation (see Smith and Venables 1988, and more recently, Anderson et al., 1995, and Barros and Martinez-Giralt 1994). This is because our model can account for endogenous product choice, whereas the aforementioned papers deal with products whose specification is exogenously given.
} 
TABLE 1

\begin{tabular}{ccc}
\hline & $B_{1}$ & $B_{2}$ \\
\hline$A_{1}$ & $a_{11}, b_{11}$ & $a_{12}, b_{12}$ \\
$A_{2}$ & $a_{21}, b_{21}$ & $a_{22}, b_{22}$ \\
\hline
\end{tabular}

\section{EQUILIBRIUM SELECTION}

The game we have described has two strict Nash equilibria for a whole range of values of $\bar{\theta}^{B}$. Standard refinements such as perfectness, properness, or strategic stability do not select among strict Nash equilibria. There is a notable exception, however, which is the concept of risk-dominance introduced by Harsanyi and Selten (1988). Let a $2 \times 2$ game with the payoff matrix as in Table 1 . The payoffs of this game are such that $E_{1}=\left(A_{1}, B_{1}\right)$ and $E_{2}=\left(A_{2}, B_{2}\right)$ are strict Nash equilibria. Let $L A_{1}=a_{11}-a_{21}$, that is $L A_{1}$ is the gain made by player $A$ by predicting rightly that the other player will play $E_{1}$ (and best responding to the prediction) instead of predicting wrongly that the other player will play $E_{2}$ (and best responding to the prediction). Similarly, let $L B_{1}=b_{11}-b_{12}, L A_{2}=a_{22}-a_{12}, L B_{2}=b_{22}-b_{21}$. We say that equilibrium $E_{1}$ risk dominates equilibrium $E_{2}$ when $L A_{1} L B_{1}>L A_{2} L B_{2}$. Therefore, the risk dominance concept selects the equilibrium that yields the highest gains to the players for a correct forecast of the equilibrium.

Besides the intuition and the axiomatization provided by Harsanyi and Selten, there are more reasons why risk dominance could be considered a good equilibrium selection criterion (see Kandori et al., 1993, and Carlsson and van Damme 1993). Perhaps the most appealing argument for risk dominance is that in experiments performed by Van Huyck et al., (1990) for a pure coordination game, the risk-dominant equilibrium is the one selected by actual players.

For the game under consideration, the risk dominance criterion selects the equilibrium with persistence of leadership. ${ }^{10}$ Let $E_{1}$ be the persistence of leadership equilibrium and $E_{2}$ the leapfrogging equilibrium. Recall that $A$ is the country with higher preference for quality and $B$ the country with lower preference for quality.

In our case $a_{11}=\pi_{1}\left(q_{A}, q_{B}\right), a_{21}=\pi_{1}\left(q_{A}^{\prime}, q_{B}\right), a_{12}=\pi_{1}\left(q_{A}, q_{B}^{\prime}\right)$ and $a_{22}=$ $\pi_{2}\left(q_{B}^{\prime}, q_{A}^{\prime}\right)$. Also $b_{11}=\pi_{2}\left(q_{A}, q_{B}\right), b_{21}=\pi_{2}\left(q_{A}^{\prime}, q_{B}\right), b_{12}=\pi_{2}\left(q_{A}, q_{B}^{\prime}\right)$ and $b_{22}=$ $\pi_{1}\left(q_{B}^{\prime}, q_{A}^{\prime}\right)$. With segmented markets $\pi_{1}, \pi_{2}$ are given by equations (13), (13').

In our case, $L A_{1}$ is what player $A$ gains by forecasting rightly that the other player will play the persistence of leadership equilibrium, instead of forecasting wrongly that the other equilibrium arises. The interpretation of $L B_{1}, L A_{2}$ and $L B_{2}$ is analogous. Figure 5 shows that $L A_{1}>L B_{2}$ and $L B_{1}>L A_{2}$ (except when $\bar{\theta}_{B}=10$, the symmetric case. ${ }^{11}$

This equilibrium selection can be interpreted in a strong way or in a weak way. The strong interpretation is that we will never (or rarely) observe players choosing the strategies that lead to an equilibrium that is not selected. The weak interpretation is that the likelihood of observing players using the strategies that lead to each

\footnotetext{
${ }^{10}$. In the limiting case where the two countries have equal populations, risk dominance predicts that the mixed strategy equilibrium will be the one played.

${ }^{11}$ Note that the figure is drawn only for those parameter values where both equilibria exist.
} 


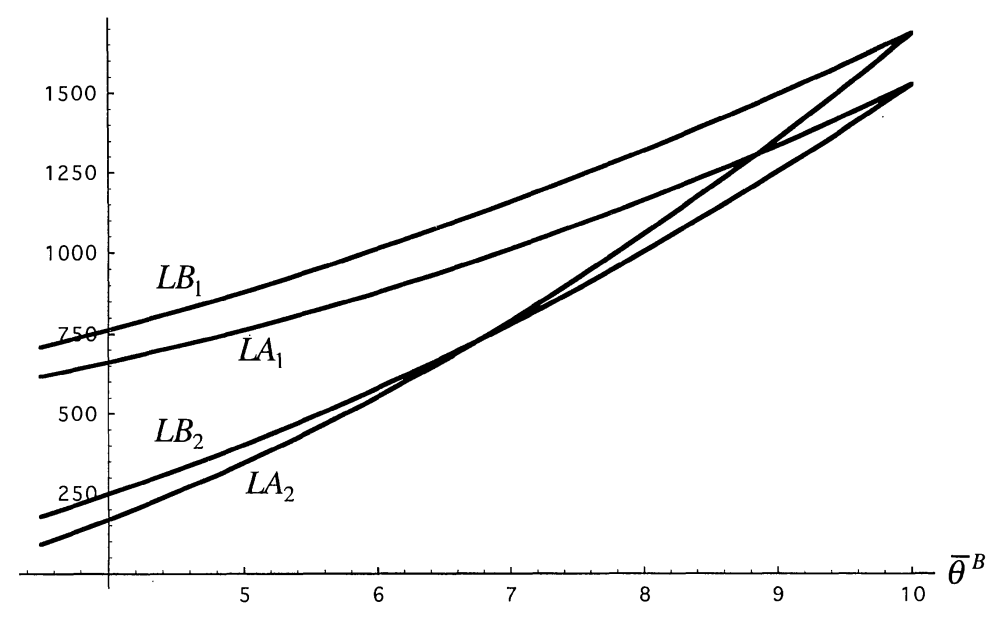

FIGURE 5

RISK DOMINANCE COMPARISONS

equilibrium is related to the difference $L A_{1} L B_{1}-L A_{2} L B_{2}$. The larger this difference, the more likely it is that we will observe players using the $E_{1}$ strategies. We feel that the weak interpretation is more reasonable, not only because it is more difficult to reject, but also because most of the reasons in favor of risk dominance involve uncertainty or a certain lack of rationality (Harsanyi and Selten 1988, p. 89). In such circumstances it would be hard to expect the strong interpretation to be satisfied.

\section{CONCLUSIONS}

The impact of international trade on asymmetric economies is an important issue as shown, for instance, by the debates which take place in North America (for example, over NAFTA) and the European Union. Similarly, it is still an open question whether less advanced countries can make up for their disadvantages in international competition. Our analysis reveals that lagging countries may be able to catch up with the more advanced countries if they are willing to make sufficiently large investments in research and development, at least when they have access to the same technology. However, this does not occur when the initial quality gap is too large. ${ }^{12}$ Furthermore, our discussion of the equilibrium selection suggests that the

${ }^{12}$ In a completely different setting, Rodrik (1994) finds results that are reminiscent of ours. If an economy has sufficiently low (high) skill level of its workforce, it will specialize only in the low-technology (respectively, high-technology) goods. However, for intermediate levels of the skill level, multiple equilibria are possible, and an economy may specialize in either low- or high-technology goods. 
leading countries are likely to keep their leadership, even when leapfrogging is also an equilibrium.

Our analysis is incomplete in several respects. First, it would be interesting to extend the analysis to the case of several firms in each country. Second, we do not deal with the impact of trade on the labor market. One may expect workers of the poorer country to be less productive, thus making our assumption that firms have access to the same technology somewhat problematic. The key question is then to determine where the technological innovations take place and where plants are located.

\section{APPENDIX}

\section{MONOPOLY IN AUTARKY AS AN ENDOGENOUS MARKET STRUCTURE}

In the Appendix we determine the values of the parameters for which a natural monopoly would arise in each country when economies are closed. In other words, we show that a monopoly is the endogenous market structure in both countries under some assumptions on fixed costs and taste parameters.

A monopolist in country $j(j=A, B)$ would choose the price and quality given by (6) and (7). It then earns a profit $\pi_{j}=.0312 S_{j}^{2} \bar{\theta}_{j}^{4}-F$, where $F$ is a fixed cost that must be incurred to begin production (but that the firms do not have to pay when the trade game starts), regardless of the quality chosen.

If two firms were to enter the market under autarky, the equilibrium firms' profits would be given by $\pi_{1 j}=.0244 S_{j}^{2} \bar{\theta}_{j}^{4}-F$ and $\pi_{2 j}=.0015 S_{j}^{2} \bar{\theta}_{j}^{4}-F$ (see Motta 1993). Hence, for only one firm to be in each market, we must have $.0015 S_{j}^{2} \theta_{j}^{4}<F<$ $.0312 S_{j}^{2} \theta_{j}^{4}$. Since this condition must hold for both countries, and given the assumption that $S_{B}=\bar{\theta}_{A} S_{A} / \bar{\theta}_{B}$ and $S_{A}=1$, it must be that $.0015 \theta_{A}^{4}<.0312 \bar{\theta}_{B}^{2} \bar{\theta}_{A}^{2}$, which amounts to $\bar{\theta}_{B}>.21926 \bar{\theta}_{A}$.

\section{REFERENCES}

Anderson, S.P., N. SChmitT, AND J.-F. Thisse, "Who Benefits from Antidumping Legislation?" Journal of International Economics, 38 (1995), 321-337.

Barros, P.P. AND X. Martinez-Giralt, "Taste for Imports and Market Integration," mimeo, Universitat Autonoma de Barcelona, 1994.

Brezis, E.S., P.R. KRUGMAN, AND D. Tsiddon, "Leapfrogging in International Competition: A Theory of Cycles in National Technological Leadership," American Economic Review 83 (1993), 1211-1219.

Budd, C., C. HARRIS, AND J. VICKERS, "A Model of the Evolution of Dupoly: Does the Asymmetry Between Firms Tend to Increase or Decrease?" Review of Economic Studies 60 (1993), 543-573.

Carlsson, H. and E. van Damme, "Global Games and Equilibrium Selection," Econometrica, 61 (1993), 989-1018.

Dasgupta, P. AND J. STIGLitz, "Learning-by-Doing, Market Structure and Industrial and Trade Policy," Oxford Economic Papers, 40 (1988), 246-268.

DevereuX, M.B. AND B.J. LAPHAM, "The Stability of Economic Integration and Endogenous Growth," Quarterly Journal of Economics, 109 (1994), 299-305.

Dinopoulos, E., "A Formalization of the "Biological" Model of Trade in Similar Products," Journal of International Economics, 25 (1988), 95-110. 
Flam, H. And E. Helpman, "Vertical Product Differentiation and North-South Trade," American Economic Review, 77 (1987), 810-822.

GRUBER, H., "Persistence of Leadership in Product Innovation," Journal of Industrial Economics, 40 (1992), 359-375.

Harsanyi, J.C. and R. Selten, A General Theory of Equilibrium in Games (Cambridge, MA: The MIT Press, 1988).

KANDORI, M., G.J. MAIlATH, AND R. RoB, "Learning, Mutation and Long-Run Equilibria in Games," Econometrica, 61 (1993), 29-56.

Krugman, P.R., "Scale Economies, Product Differentiation and the Pattern of Trade," American Economic Review, 70 (1980), 950-959.

LindER, S., An Essay on Trade and Transformation (New York: John Wiley, 1961).

MotTA, M., "Sunk Costs and Trade Liberalisation," Economic Journal, 102 (1992), 578-587.

- "Endogenous Quality Choice: Price vs. Quantity Competition," Journal of Industrial Economics, 41 (1993), 113-131.

- J.-F. ThisSE AND A. CABrales, "On the Persistence of Leadership or Leapfrogging in International Trade," Center for Economic Policy Research Discussion Paper 1106, London, 1995.

Nelson, R.R. AND S.G. Winter, An Evolutionary Theory of Economic Change (Cambridge, MA: Harvard University Press, 1985).

Ohyama, M. AND R.W. Jones, "Technology Choice, Overtaking and Comparative Advantage," Seminar Paper 94-07, Centre for International Economic Studies, University of Adelaide, 1994.

Porter, M.E., The Competitive Advantage of Nations (London: MacMillan, 1990).

ReINGANUM, J., "Innovation and Industry Evolution," Quarterly Journal of Economics, 100 (1985), 81-99.

$\rightarrow$ Rivera-BÁtiz, L. AND .D. XIE, "Integration among Inequals," Regional Science and Urban Economics, 23 (1993), 337-354.

RodrIK, D., "Do Low-Income Countries Have a High-Wage Option?" Center for Economic Policy Research Discussion Paper No. 862, 1994.

ShAKED, A. AND J. SutTon, "Natural Oligopolies and International Trade," in H. Kierzkowski, ed., Monopolistic Competition and International Trade (Oxford: Oxford University Press, 1984).

$\rightarrow$ Smith, A. AND A. Venables, "Completing the Internal Market in the European Community: Some Industry Simulations," European Economic Review, 32 (1988), 1501-1525.

TIROLE, J., The Theory of Industrial Organization (Cambridge, MA: MIT Press, 1988).

VAN HuYCK, J., R. BATTALIO, AND R. BeIL, "Tacit Coordination Games, Strategic Uncertainty, and Coordination Failure," American Economic Review, 80 (1990), 234-249.

$\rightarrow$ VenABLES, A., "International Capacity Choice and National Market Game," Journal of International Economics, 29 (1990), 23-42. 